\title{
Empathy, stress and professional burnout syndrome suffered by psychiatric nurses
}

\author{
Empatia, stres a wypalenie zawodowe u pielęgniarek psychiatrycznych
}

\author{
Health Psychology Department, Andrzej Frycz Modrzewski Krakow University, Krakow, Poland \\ Correspondence: Ewa Wilczek-Rużyczka, Andrzej Frycz Modrzewski Krakow University, Gustawa Herlinga-Grudzińskiego 1, 30-705 Kraków, Poland, tel.: +48 660 913 017, e-mail: ewaroz0@poczta.onet.pl \\ Drhab. Ewa Wilczek-Rużyzza, prof. nadzw., Katedra Psychologii Zdrowia, Krakowska Akademia im. Andrzeja Frycza Modrzewskiego, ul. Gustawa Herlinga-Grudzińskkiego 1, 30-705 Kraków, tel.: + 48660 913 017, \\ e-mail:ewaroz0@poczta.onet.pl
}

\begin{abstract}
Objective: The objective of the paper was an analysis of relations between the level of empathy, styles of coping with stress, and professional burnout syndrome in psychiatric nurses. Materials and methods: The study involved 64 members of nursing staff who usually (90.6\%) work in 12-hour shifts in psychiatric wards in southern Poland, mostly women (93.8\%). The average age of the entire group was 42.91 years, and more than half had a higher nursing education (54.7\%). The Interpersonal Reactivity Index (IRI) by M.H. Davis for the purpose of measurement of empathy level in four scales, the Coping Inventory for Stressful Situations (CISS) by N.S. Endler and J.D.A. Parker that distinguishes three different styles of coping with stress, and the Maslach Burnout Inventory (MBI) by Ch. Maslach to measure three burnout dimensions, were used for the study. Results: Regression analysis showed that the significant professional burnout predictors were emotionoriented style, search for social contact and avoidance-oriented style, and two out of four types of empathy: personal distress, and also assumption of someone else's perspective, the only one of the above-mentioned predictors that prevents burnout. Conclusions: Among the psychiatric nurses who participated in the study, those characterised by a higher empathy level more often choose more constructive styles of coping with stress, and are less vulnerable to professional burnout. Consequently, the legitimacy of introducing empathy training and educational programmes related to coping with stress in the educational process was confirmed.
\end{abstract}

Keywords: empathy, burnout, stress, psychiatric nurses

Cel: Celem pracy była analiza związków między poziomem empatii, stylami radzenia sobie ze stresem a zespołem wypalenia zawodowego u pielęgniarek psychiatrycznych. Materiał i metoda: W badaniu uczestniczyły 64 osoby, pracujące zazwyczaj (90,6\%) w systemie zmianowym 12-godzinnym na oddziałach psychiatrycznych w południowej Polsce, w zdecydowanej większości kobiety $(93,8 \%)$. Średnia wieku dla całej grupy wynosiła 42,91 roku, a nieco ponad połowa uczestników miała wyższe wykształcenie pielęgniarskie (54,7\%). W badaniach wykorzystano: Indeks Reaktywności Interpersonalnej (Interpersonal Reactivity Index, IRI) M.H. Davisa do pomiaru poziomu empatii w czterech skalach, Kwestionariusz Radzenia Sobie w Sytuacjach Stresowych (Coping Inventory for Stressful Situations, CISS) N.S. Endlera i J.D.A. Parkera, wyróżniający trzy style radzenia sobie ze stresem, oraz Kwestionariusz Wypalenia Zawodowego (Maslach Burnout Inventory, MBI) C. Maslach do oceny trzech wymiarów wypalenia. Wyniki: Analiza regresji wykazała, że istotnymi predyktorami wypalenia zawodowego są styl skoncentrowany na emocjach, poszukiwanie kontaktów towarzyskich i styl skoncentrowany na unikaniu oraz dwie z czterech skal empatii (osobista przykrość, a także przyjmowanie cudzej perspektywy - jedyny predyktor spośród wymienionych chroniący przed wypaleniem). Wnioski: Badane pielęgniarki psychiatryczne charakteryzujące się wyższym poziomem empatii częściej wybierają konstruktywne style radzenia sobie ze stresem i są w mniejszym stopniu narażone na wypalenie zawodowe, a więc potwierdzono zasadność wprowadzenia do procesu kształcenia pielęgniarek treningu empatii i programów edukacyjnych dotyczących zapobiegania wypaleniu zawodowemu i radzenia sobie ze stresem.

Słowa kluczowe: empatia, wypalenie zawodowe, stres, pielęgniarki psychiatryczne 


\section{INTRODUCTION}

$\mathrm{I}$ n their professional work, nurses very often experience everyday stress related to the communication with patients and their families, and sometimes threats to life, and a necessity to make rapid decisions, which may lead to professional burnout (WilczekRużyczka, 2017). Thus, the ability to cope with stress and show empathy, which is of particular significance for people that provide help, are of substantial importance. According to Davis (2001), the empathic factors are genetically conditioned, and the main mechanism required for proper development of empathy is an emotional one that is certainly affected by factors related to upbringing (Strus, 2012). The study model by Davis was based on an inclusive definition, as it assumes that a typical empathetic "episode" is as follows: the observer somehow establishes contact with the observed person and then a certain kind of relation (cognitive, affective and/or behavioural) by the observer occurs.

Among many biological and psychological theories and definitions of stress, one should especially give attention to the concepts by Lazarus and Folkman, where stress is understood as a "particular relationship between a person and the environment that is evaluated by a person as overwhelming or exceeding his/her resources and constituting a threat to his/her well-being," and by Siegrist who states that the main source of professional stress is a disproportion that the employee experiences between an effort made by him/her in his/her work and the reward for such effort (Siegrist et al., 2004). It is a condition of lingering belief about an imbalance between effort and reward which may lead to serious health disorders. The authors warn that stress levels also depend on the manner in which an individual handles a stressful situation. The term "coping with stress," was introduced in the 1960s, and it is considered the most important item of a stressful situation (Grygorczyk, 2008).

Among many classifications of coping with stress, the one that should be highlighted is the one proposed by Endler and Parker (1990), who distinguished three styles of coping with stress: task-oriented, emotion-oriented, and avoidance-oriented, including engaging in replacement activities and searching for social contact.

Herbert Freudenberger is considered to be the inventor of the term "professional burnout syndrome," however attempts to define this phenomenon on the basis of parallel studies have also been made by Christina Maslach and associates (Maslach et al., 2001). According to the model developed by this team, there are three constituent dimensions of professional burnout: emotional exhaustion, depersonalisation, and lowered sense of personal achievements. Emotional exhaustion refers to the feeling experienced by a given person that he/she is too emotionally overwhelmed, and moreover his/her emotional resources have been significantly decreased.

\section{WPROWADZENIE}

$\mathrm{P}$ ielęgniarki w swej pracy na co dzień doświadczają stresu związanego z komunikacją z pacjentem i jego rodziną, a czasami z zagrożeniem życia i koniecznością podejmowania nagłych decyzji, co prowadzić może do wypalenia zawodowego (Wilczek-Rużyczka, 2017). Dlatego niebagatelne znaczenie ma umiejętność radzenia sobie ze stresem i okazywania empatii, istotnej w szczególności u osób sprawujących opiekę. Zdaniem Davisa (2001) czynniki empatyczne uwarunkowane są genetycznie, a głównym mechanizmem potrzebnym do właściwego wykształcenia się empatii jest mechanizm emocjonalny, na który niewątpliwie wpływają czynniki wychowawcze (Strus, 2012). Badawczy model Davisa został oparty na definicji inkluzywnej i zakłada, że typowy „epizod” empatyczny przebiega następująco: obserwator styka się w jakiś sposób z obserwowanym i pojawia się pewien rodzaj relacji ze strony obserwatora (poznawcza, afektywna i/lub behawioralna).

Spośród wielu teorii biologicznych i psychologicznych oraz definicji stresu na uwagę zasługują szczególnie koncepcje Lazarusa i Folkman - stres rozumiany jako „określona relacja między osobą a otoczeniem, która oceniana jest przez osobę jako obciążająca lub przekraczająca jej zasoby i zagrażająca jej dobrostanowi” - oraz Siegrista, według którego główne źródło stresu zawodowego stanowi odczuwana przez pracownika dysproporcja między wysiłkiem wkładanym w pracę a nagrodą otrzymywaną za ten wysiłek (Siegrist et al., 2004). Utrzymujące się przekonanie o nierównowadze między wysiłkiem a nagrodą prowadzić może do poważnych zaburzeń zdrowotnych. Autorzy dostrzegają, że skutki stresu zależą też od sposobu, w jaki jednostka radzi sobie $z$ sytuacją stresową. Pojęcie „radzenia sobie ze stresem" - coping, wprowadzone w latach 60 . XX wieku, uważane jest za najważniejszy element sytuacji stresowej (Grygorczyk, 2008).

Z wielu różnych klasyfikacji stylów radzenia ze stresem przybliżyć należy ujęcie Endlera i Parkera (1990), którzy wyróżnili trzy style: skoncentrowany na zadaniu, skoncentrowany na emocjach i skoncentrowany na unikaniu (w tym angażowanie się w czynności zastępcze oraz poszukiwanie kontaktów towarzyskich).

Za twórcę terminu „wypalenie zawodowe” uważa się psychologa Herberta Freudenbergera, jednak próby zdefiniowania zjawiska na podstawie prowadzonych równolegle badań podjęła Christina Maslach ze współpracownikami (Maslach et al., 2001). Według stworzonego przez ten zespół modelu na wypalenie zawodowe składają się trzy wymiary: wyczerpanie emocjonalne, depersonalizacja i obniżone poczucie osiągnięć osobistych. Wyczerpanie emocjonalne to poczucie, że jest się nazbyt obciążonym emocjonalnie, a ponadto ma się znacznie uszczuplone zasoby emocjonalne. Depersonalizacja oznacza zbyt obojętne lub negatywne reakcje na ludzi, którzy zazwyczaj stanowią grupę odbiorców usług danej osoby. 
by a decrease in performance, and an impaired sense of own competence (Maslach and Jackson, 1981).

\section{AIM OF THE PAPER}

The aim of this paper was an analysis of relations between the level of empathy, styles of coping with stress, and professional burnout syndrome suffered by psychiatric nurses.

\section{MATERIALS AND METHODS}

The protocol of the study, which was conducted in 2017, was approved by the Local Bioethics Committee at Andrzej Frycz Modrzewski Krakow University (decision No. KBKA/10/O/2017).

The study involved 64 members of nursing staff working in psychiatric wards, including 60 female nurses (93.8\%), and 4 male nurses (6.2\%). Due to a huge disproportion between the number of women and men in the study group, the results for female and male nurses were not analysed separately. Nevertheless, during the analysis of study results the sex variable was controlled, as was its relation with the dependable variables. After the lack of statistical significance was determined, the study group was treated as a whole, and not as a homogenous one, as it corresponds to the structure of the professional group of psychiatric nurses. The average age of the participants, within the age range of 27 to 60 years, was 42.91 . The longest professional seniority was 40 years, and the shortest was 4 years, whereas the average seniority in the profession was 21.34 years. Considerable variations in the respondents' age and length of service did not have a statistically significant impact on the results of dependent variables, but the author decided to control those independent variables (age and seniority), as in the literature there are no conclusive study results that refer to their effect on the results of the analysed dependent variables. Most of the study participants, specifically $57.8 \%$, indicated a city with a population over 100,000 as their place of residence, and less than every fifth participant - $18.8 \%$ - indicated a village. Slightly more than half declared having completed higher education in nursing, whether a master's degree $(35.9 \%)$ or a bachelor's degree (18.8\%), and the remaining group declared secondary education (45.3\%), whereas only a minor proportion declared having a degree in a different major (6.3\%). The majority of the participants, 58 in total (90.6\%), work in a 12-hour shift system, whereas the remaining 6 nurses (9.4\%) work in a single-shift system.

The following tools were used in the study:

1. Interpersonal Reactivity Index (IRI) by M.H. Davis (2001) for the purpose of measuring empathy in the scales of assuming a perspective, empathic care, personal distress, and fantasy.

2. Coping Inventory for Stressful Situations (CISS) by N.S. Endler and J.D.A. Parker (1990) that distinguishes three styles of coping with stress: task-oriented, emotion-oriented, and avoidance-oriented,
Obniżone poczucie osiągnięć osobistych charakteryzuje się spadkiem wydajności pracy i poczucia własnej kompetencji (Maslach i Jackson, 1981).

\section{CEL PRACY}

Celem pracy była analiza związków między poziomem empatii, stylami radzenia sobie ze stresem a zespołem wypalenia zawodowego u pielegniarek psychiatrycznych.

\section{MATERIAŁ I METODY}

Projekt badań, przeprowadzonych w 2017 roku, został zatwierdzony przez Komisję Bioetyczną Krakowskiej Akademii im. Andrzeja Frycza Modrzewskiego (decyzja nr KBKA/10/O/2017).

W badaniu uczestniczyły 64 osoby pracujące na oddziałach psychiatrycznych: 60 kobiet $(93,8 \%)$ - pielęgniarek oraz 4 mężczyzn $(6,2 \%)$ - pielęgniarzy. Z uwagi na dużą dysproporcję liczby kobiet i mężczyzn w badanej grupie nie analizowano oddzielnie wyników dla pielęgniarek i pielęgniarzy psychiatrycznych. Niemniej w analizie wyników kontrolowano zmienną „płeć” i jej związek ze zmiennymi zależnymi, a po stwierdzeniu braku istotności rozpatrywano grupę w całości, a nie jako homogenną, gdyż odpowiada ona strukturze grupy zawodowej pielęgniarek psychiatrycznych. Średnia wieku badanych, mieszczącego się w granicach 27-60 lat, wynosiła dla całej grupy 42,91 roku. Najdłuższy staż pracy to 40 lat, najkrótszy - 4 lata, średni zaś - 21,34 roku. Duże zróżnicowanie wieku i stażu pracy badanych nie wpływało istotnie statystycznie na wyniki zmiennych zależnych, a kontrolowanie wskazanych zmiennych niezależnych (wiek i staż pracy) wynikało $\mathrm{z}$ faktu, że w literaturze nie ma jednoznacznych wyników badań dotyczących ich wpływu na analizowane zmienne zależne. Jako miejsce swojego zamieszkania większość badanych - 57,8\% - wskazała miasto powyżej 100 tys., a mniej niż co piąta osoba $18,8 \%$ - podała, że mieszka na wsi. Nieco ponad połowa grupy miała wyższe wykształcenie pielęgniarskie, albo magisterskie (35,9\%), albo licencjackie $(18,8 \%$ ), a pozostali uczestnicy - średnie (45,3\%), przy czym nieliczni $(6,3 \%)$ ukończyli studia wyższe o innym profilu kształcenia. Najwięcej badanych, 58 osób (90,6\%), pracowało w systemie zmianowym 12-godzinnym, a 6 osób $(9,4 \%)$ w systemie jednozmianowym.

W badaniach wykorzystano następujące narzędzia:

1. Indeks Reaktywności Interpersonalnej (Interpersonal Reactivity Index, IRI) M.H. Davisa (2001) do pomiaru poziomu empatii w skalach: przyjmowanie perspektywy, empatyczna troska, osobista przykrość i fantazja.

2. Kwestionariusz Radzenia Sobie w Sytuacjach Stresowych (Coping Inventory for Stressful Situations, CISS) N.S. Endlera i J.D.A. Parkera (1990), wyróżniający trzy style radzenia sobie ze stresem: skoncentrowany na zadaniu, skoncentrowany na emocjach i skoncentrowany 
including engaging in replacement activities or searching for social contact.

3. Maslach Burnout Inventory (MBI) for the measurement of three dimensions: emotional exhaustion, depersonalisation, and lowered sense of personal achievements (Maslach and Jackson, 1981).

To verify the results obtained, basic statistical procedures were applied to describe variables, and in order to show a correlation between variables, $r$-Pearson linear correlation coefficient was used. In turn, to analyse the influence of empathy and styles of coping with stress on professional burnout, the method of regression analysis was applied. A dependent variable in the regression analysis was a dimension distinguished by principal component analysis performed for three dimensions of professional burnout.

\section{RESULTS}

The Shapiro-Wilk's test for normality results (Tab. 1) showed that all variables except the IRI scale - fantasy and CISS - avoidance-oriented style, were characterised by normal distribution.

Due to the fact that a relatively small sample was analysed $(N=64)$, and distribution histograms did not allow rejecting the hypothesis of their normality, the author examined the values of kurtosis and skewness (Tab. 2). In both cases, the values were in the range of $<-1 ; 1>$ (George and Mallery, 2010), so no significant differences were to be expected between the parametric and non-parametric tests results. Consequently, parametric tests were used for further analysis.

\section{Relations between empathy, stress and professional burnout in the group of participating psychiatric nurses}

Firstly, an analysis was performed, involving the $r$-Pearson correlation test between the IRI empathy scale and a MBI professional burnout dimension as listed in Tab. 3. According to this analysis, assuming a perspective (IRI scale) was significantly negatively correlated with two MBI dimensions: depersonalisation $(r=-0.32 ; p<0.05$, moderate correlation), and lowered sense of personal achievements $(r=0.29 ; p<0.05$, low correlation $)$ - despite a positive correlation sign, due to the reversed nature of values of the latter dimension. The reason for the above relations may be that individuals with a more developed cognitive empathy (perspective taking) are emotionally conscious, able to control their emotions, take perspective as well as understand the patient, and thus do not allow patient dehumanisation. There was also a positive correlation between the level of personal distress experienced at work and professional exhaustion ( $r=0.32 ; p<0.05$, moderate correlation). It can be assumed that people characterised by emotional empathy (personal distress) take over the patient's negative emotions when dealing with them, and are therefore more na unikaniu (w tym angażowanie się w czynności zastępcze oraz poszukiwanie kontaktów towarzyskich).

3. Kwestionariusz Wypalenia Zawodowego C. Maslach (Maslach Burnout Inventory, MBI) do oceny trzech wymiarów: wyczerpania emocjonalnego, depersonalizacji i obniżenia poczucia osiągnięć osobistych (Maslach i Jackson, 1981).

Aby zweryfikować uzyskane wyniki, zastosowano podstawowe procedury statystyczne opisujące zmienne, a w celu wykazania związku między zmiennymi korzystano z testu współczynnika korelacji liniowej $r$-Pearsona. Analizując wpływ empatii i stylów radzenia sobie ze stresem na wypalenie zawodowe, skorzystano $\mathrm{z}$ analizy regresji. Zmienną zależną w analizie regresji był wymiar wyodrębniony za pomocą analizy głównych składowych dokonanej na trzech wymiarach wypalenia zawodowego.

\section{WYNIKI}

Wyniki testu normalności Shapiro-Wilka wskazywały (tab. 1), że wszystkie zmienne poza skalą IRI - fantazja oraz CISS - styl skoncentrowany na unikaniu cechują się rozkładem normalnym.

Ponieważ badano stosunkowo małą próbkę $(N=64)$, a histogramy rozkładów nie pozwalały na jednoznaczne odrzucenie hipotezy o ich normalności, zapoznano się z wartościami kurtoz i skośności (tab. 2). W obu przypadkach wartości mieściły się w przedziale $<-1 ; 1>$ (George i Mallery, 2010), w związku z czym nie powinny wystąpić znaczące różnice między wynikami testów parametrycznych i nieparametrycznych. Dlatego w dalszej analizie posługiwano się testami parametrycznymi.

\section{Związek między empatią, stresem i wypaleniem zawodowym w grupie badanych pielęgniarek psychiatrycznych}

W pierwszej kolejności przeanalizowano wyniki testu korelacji r-Pearsona między skalą empatii IRI a wymiarami wypalenia zawodowego według MBI, zestawione w tab. 3. $\mathrm{Z}$ analizy wynika, że przyjmowanie perspektywy (skala IRI) było istotnie ujemnie skorelowane $\mathrm{z}$ dwoma wymiarami MBI: depersonalizacją ( $r=-0,32 ; p<0,05$, umiarkowany związek), a także obniżonym poczuciem osiągnięć osobistych ( $r=0,29 ; p<0,05$, słaby związek) - pomimo dodatniego znaku korelacji, z uwagi na odwrócony charakter wartości ostatniego $\mathrm{z}$ wymienionych wymiarów. Przyczyną powyższych związków może być to, że osoby z bardziej rozwiniętą empatią poznawczą (przyjmowanie perspektywy) mają świadomość emocji i ich kontrolowania, przyjmowania perspektywy oraz rozumienia pacjenta, z czym wiąże się niedopuszczanie do dehumanizacji chorego. Wystąpiła również istotna dodatnia korelacja między odczuwaną osobistą przykrością w pracy a wyczerpaniem emocjonalnym ( $r=0,32 ; p<0,05$, umiarkowany związek). Można przypuszczać, że osoby charakteryzujące się empatią 


\begin{tabular}{|l|c|c|c|}
\hline \multirow{2}{*}{} & \multicolumn{3}{|c|}{ Shapiro-Wilk } \\
\cline { 2 - 4 } & $\begin{array}{c}\text { Statistics } \\
\text { Statystyka }\end{array}$ & $\mathbf{d f}$ & $\boldsymbol{p}$ \\
\hline $\begin{array}{l}\text { MBI - emotional exhaustion } \\
\text { MBI - wypalenie emocjonalne }\end{array}$ & 0.98 & 64 & 0.45 \\
\hline $\begin{array}{l}\text { MBI - depersonalisation } \\
\text { MBI - depersonalizacja }\end{array}$ & 0.97 & 64 & 0.07 \\
\hline $\begin{array}{l}\text { MBI - lack of job satisfaction } \\
\text { MBI - brak satysfakcji zawodowej }\end{array}$ & 0.99 & 64 & 0.83 \\
\hline $\begin{array}{l}\text { IRI - assuming a perspective } \\
\text { IRI - przyjmowanie perspektywy }\end{array}$ & 0.97 & 64 & 0.07 \\
\hline $\begin{array}{l}\text { IRI - fantasy } \\
\text { IRI - fantazja }\end{array}$ & $\mathbf{0 . 9 4}$ & $\mathbf{6 4}$ & $<\mathbf{0 . 0 1}$ \\
\hline $\begin{array}{l}\text { IRI - empathic care } \\
\text { IRI - empatyczna troska }\end{array}$ & 0.97 & 64 & 0.13 \\
\hline $\begin{array}{l}\text { IRI - personal distress } \\
\text { IRI - osobista przykró́ć }\end{array}$ & 0.98 & 64 & 0.32 \\
\hline $\begin{array}{l}\text { CISS - task-oriented style } \\
\text { CISS - styl skoncentrowany na zadaniu }\end{array}$ & 0.97 & 64 & 0.08 \\
\hline $\begin{array}{l}\text { CISS - emotion-oriented style } \\
\text { CISS - styl skoncentrowany na emocjach }\end{array}$ & 0.98 & 64 & 0.28 \\
\hline $\begin{array}{l}\text { CISS - avoidance-oriented style } \\
\text { CISS - styl skoncentrowany na unikaniu }\end{array}$ & $\mathbf{0 . 9 3}$ & $\mathbf{6 4}$ & $<\mathbf{0 . 0 1}$ \\
\hline $\begin{array}{l}\text { CISS - engagement in replacement activities } \\
\text { CISS - angażowanie się w czynności zastępcze }\end{array}$ & 0.97 & 64 & 0.14 \\
\hline $\begin{array}{l}\text { CISS - search for social contact } \\
\text { CISS - poszukiwanie kontaktów towarzyskich }\end{array}$ & 0.96 & 64 & 0.06 \\
\hline $\begin{array}{l}\text { Years of service } \\
\text { Liczba przepracowanych lat }\end{array}$ & 0.98 & 64 & 0.57 \\
\hline
\end{tabular}

Tab. 1. Test of normality results for the analysed variables Tab. 1. Wyniki testu normalności analizowanych zmiennych

According to the analysis of correlations between the application of styles of coping with stress (CISS) and professional burnout dimensions (MBI) listed in Tab. 4, professional burnout in the dimension of emotional exhaustion was significantly positively correlated with both emotion-oriented style ( $r=0.60 ; p<0.001$, strong effect), style based on engaging in replacement activities $(r=0.36$; $p<0.01$, moderate effect), and avoidance-oriented style $(r=0.25 ; p<0.05$, weak effect). On the other hand, in the case of professional

\begin{tabular}{|l|c|c|}
\hline & $\begin{array}{c}\text { Skewness } \\
\text { Skośność }\end{array}$ & $\begin{array}{c}\text { Kurtosis } \\
\text { Kurtoza }\end{array}$ \\
\hline $\begin{array}{l}\mathrm{MBI} \text { - emotional exhaustion } \\
\mathrm{MBI} \text { - wypalenie emocjonalne }\end{array}$ & 0.12 & -0.55 \\
\hline $\begin{array}{l}\mathrm{MBI} \text { - depersonalisation } \\
\mathrm{MBI} \text { - depersonalizacja }\end{array}$ & 0.43 & -0.43 \\
\hline $\begin{array}{l}\mathrm{MBI} \text { - lack of job satisfaction } \\
\text { MBI - braksatysfakcji zawodowej }\end{array}$ & 0.15 & -0.04 \\
\hline $\begin{array}{l}\text { IRI - assuming a perspective } \\
\text { IRI - przyjmowanie perspektywy }\end{array}$ & -0.61 & 0.48 \\
\hline $\begin{array}{l}\text { IRI - fantasy } \\
\text { IRI - fantazja }\end{array}$ & $-\mathbf{0 . 9 0}$ & $\mathbf{0 . 7 8}$ \\
\hline $\begin{array}{l}\text { IRI - empathic care } \\
\text { IRI - empatyczna troska }\end{array}$ & -0.32 & -0.44 \\
\hline $\begin{array}{l}\text { IRI - personal distress } \\
\text { IRI - osobista przykró́ć }\end{array}$ & -0.42 & 0.18 \\
\hline $\begin{array}{l}\text { CISS - task-oriented style } \\
\text { CISS - styl skoncentrowany na zadaniu }\end{array}$ & -0.39 & 1.15 \\
\hline $\begin{array}{l}\text { CISS - emotion-oriented style } \\
\text { CISS - styl skoncentrowany na emocjach }\end{array}$ & -0.54 & 0.69 \\
\hline $\begin{array}{l}\text { CISS - avoidance-oriented style } \\
\text { CISS - styl skoncentrowany na unikaniu }\end{array}$ & $-\mathbf{0 . 9 8}$ & $\mathbf{0 . 7 5}$ \\
\hline $\begin{array}{l}\text { CISS - engagement in replacement activities } \\
\text { CISS - angażowanie się w czynności zastępcze }\end{array}$ & -0.23 & 0.02 \\
\hline $\begin{array}{l}\text { CISS - search for social contact } \\
\text { CISS - poszukiwanie kontaktów towarzyskich }\end{array}$ & -0.50 & 0.15 \\
\hline $\begin{array}{l}\text { Years of service } \\
\text { Liczba przepracowanych lat }\end{array}$ & 0.31 & 0.38 \\
\hline
\end{tabular}

Tab. 2. Skewness and kurtosis values for the analysed data Tab. 2. Wartości skośności i kurtoz analizowanych zmiennych

emocjonalną (osobista przykrość) w kontakcie z pacjentem przejmują jego negatywne emocje, czego następstwem jest większe wyczerpanie emocjonalne i energetyczne.

Analizując związki między stosowaniem stylów radzenia sobie ze stresem (CISS) a wymiarami wypalenia zawodowego (MBI), przedstawione w tab. 4, stwierdzono, że wypalenie zawodowe w wymiarze „wyczerpanie emocjonalne" było istotnie dodatnio skorelowane zarówno ze stylem skoncentrowanym na emocjach $(r=0,60$;

\begin{tabular}{|c|c|c|c|c|c|c|}
\hline & \multicolumn{2}{|c|}{$\begin{array}{l}\text { MBI- emotional exhaustion } \\
\text { MBI - wyczerpanie emocjonalne }\end{array}$} & \multicolumn{2}{|c|}{$\begin{array}{c}\mathrm{MBI} \text { - depersonalisation } \\
\mathrm{MBI} \text { - depersonalizacja }\end{array}$} & \multicolumn{2}{|c|}{$\begin{array}{c}\text { MBI - lowered sense of personal } \\
\text { achievements } \\
\text { MBI - obniżone poczucie osiagnięć osobistych }\end{array}$} \\
\hline & $r$ & $p$ & $r$ & $p$ & $r$ & $p$ \\
\hline $\begin{array}{l}\text { IRI - assuming a perspective } \\
|R| \text { - przyjmowanie perspektywy }\end{array}$ & -0.10 & 0.42 & -0.32 & $<0.05$ & 0.29 & $<0.05$ \\
\hline $\begin{array}{l}\text { IRI - empathic care } \\
|R| \text { - empatyczna troska }\end{array}$ & 0.13 & 0.30 & -0.21 & 0.10 & 0.01 & 0.96 \\
\hline $\begin{array}{l}\text { IRI - personal distress } \\
|R| \text { - osobista przykrość }\end{array}$ & 0.32 & $<0.05$ & 0.03 & 0.84 & -0.08 & 0.55 \\
\hline $\begin{array}{l}\text { IRI - fantasy } \\
|R| \text { - fantazja }\end{array}$ & 0.16 & 0.21 & -0.01 & 0.92 & -0.02 & 0.86 \\
\hline
\end{tabular}

Tab. 3. Results of the test of correlations between IRI empathy scale and MBI professional burnout dimensions

Tab. 3. Wyniki testu związków między skala empatii IRI a wymiarami wypalenia zawodowego MBI 
burnout in the dimension of depersonalisation, there was a negative correlation with two styles: the task-oriented style ( $r=-0.36 ; p<0.001$, moderate effect) and search for social contact ( $r=-0.34 ; p<0.05$, moderate effect), and also a significant, but positive correlation with two other styles: emotion-oriented ( $r=0.43 ; p<0.001$, moderate effect) and engaging in replacement activities $(r=0.42 ; p<0.001$, moderate). According to the analysis of a dimension of lowered sense of personal achievements, due to the reversed nature of this dimension, a statistically significant negative correlation was confirmed (with a positive sign) with two styles: task-oriented style $(r=0.45 ; p<0.001$, moderate effect) and search for social contact ( $r=0.25 ; p<0.05$, weak effect), whereas a significant positive correlation (with a negative sign) was confirmed for two styles: emotion-oriented ( $r=-0.32$; $p<0.05$, moderate effect) and engagement in replacement activities ( $r=-0.39 ; p<0.001$, moderate effect).

Therefore, the relations that were presented in Tab. 4 confirm that individuals applying constructive styles of coping with stress have the necessary personal resources and are able to handle difficulties and make adequate decisions in difficult situations, and as a result are less vulnerable to professional burnout.

According to the results of $r$-Pearson correlation between the application of styles of coping with stress according to the CISS and the IRI empathy scale as listed in Tab. 5, there is a significant statistically compliant relation between the assumption of someone else's perspective and the task-oriented style ( $r=0.34 ; p<0.05$, moderate effect), and a significant opposite relation between the assumption of someone else's perspective and engagement in replacement activities ( $r=-0.37 ; p<0.05$, moderate effect) and the avoidanceoriented style $(r=-0.25 ; p<0.05$, weak effect). Moreover, there is a significant positive relation between the tendency to experience personal distress as a reaction to powerful negative experiences of other people and the task-oriented style $(r=0.43 ; p<0.01$, moderate effect). $p<0,001$, silny efekt), stylem polegającym na angażowaniu się w czynności zastępcze $(r=0,36$; $p<0,01$, umiarkowany efekt), jak i stylem skoncentrowanym na unikaniu ( $r=0,25 ; p<0,05$, słaby efekt). Z kolei w przypadku wymiaru „depersonalizacja” wykazano istotną ujemną korelację z dwoma stylami: stylem skoncentrowanym na zadaniu ( $r=-0,36 ; p<0,001$, umiarkowany efekt) oraz poszukiwaniem kontaktów towarzyskich $(r=-0,34$; $p<0,05$, umiarkowany efekt), jak również istotną, ale dodatnią korelację $\mathrm{z}$ dwoma innymi stylami: skoncentrowaniem na emocjach $(r=0,43 ; p<0,001$, umiarkowany efekt) i angażowaniem się w czynności zastępcze $(r=0,42 ; p<0,001$, umiarkowany efekt). W analizie dotyczącej wymiaru „obniżone poczucie osiągnięć osobistych” potwierdzono istotną statystycznie ujemną korelację (przy dodatnim znaku) $\mathrm{z}$ dwoma stylami: skoncentrowaniem na zadaniu ( $r=0,45 ; p<0,001$, umiarkowany efekt) i poszukiwaniem kontaktów towarzyskich $(r=0,25 ; p<0,05$, słaby efekt), a także istotną korelację dodatnią (przy ujemnym znaku) z dwoma innymi stylami: skoncentrowaniem na emocjach ( $r=-0,32 ; p<0,05$, umiarkowany efekt) i angażowaniem się w czynności zastępcze $(r=-0,39 ; p<0,001$, umiarkowany efekt).

Związki wykazane w tab. 4 potwierdzają więc, że osoby stosujące konstruktywne style radzenia sobie ze stresem dysponują zasobami osobowymi i potrafią podejmować adekwatne decyzje w trudnych sytuacjach, co sprawia, że są w mniejszym stopniu narażone na wypalenie.

Analizując wyniki korelacji $r$-Pearsona między stosowaniem stylów radzenia sobie ze stresem według CISS a skalą empatii IRI, zawarte w tab. 5, stwierdzono istotny statystycznie zgodny związek między przyjmowaniem cudzej perspektywy a stylem skoncentrowanym na zadaniu $(r=0,34 ; p<0,05$, umiarkowany efekt) oraz istotny przeciwny związek między przyjmowaniem cudzej perspektywy a angażowaniem się w czynności zastępcze $(r=-0,37 ; p<0,05$, umiarkowany efekt) i stylem

\begin{tabular}{|c|c|c|c|c|c|c|}
\hline & \multicolumn{2}{|c|}{$\begin{array}{l}\mathrm{MBI} \text { - emotional exhaustion } \\
\mathrm{MBI} \text { - wyczerpanie emocjonalne }\end{array}$} & \multicolumn{2}{|c|}{$\begin{array}{c}\mathrm{MBI} \text { - depersonalisation } \\
\mathrm{MBI} \text { - depersonalizacja }\end{array}$} & \multicolumn{2}{|c|}{$\begin{array}{l}\text { MBI - lowered sense of personal } \\
\text { achievements } \\
M B I \text { - obniżone poczucie osiagnięć osobistych }\end{array}$} \\
\hline & $r$ & $p$ & $r$ & $p$ & $r$ & $p$ \\
\hline $\begin{array}{c}\text { CISS - task-oriented style } \\
\text { CISS - styl skoncentrowany na zadaniu }\end{array}$ & -0.20 & 0.11 & -0.36 & $<0.01$ & 0.45 & $<0.001$ \\
\hline $\begin{array}{l}\text { CISS - emotion-oriented style } \\
\text { CISS - styl skoncentrowany na emocjach }\end{array}$ & 0.60 & $<0.001$ & 0.43 & $<0.001$ & -0.32 & $<0.05$ \\
\hline $\begin{array}{l}\text { CISS - engagement in replacement activities } \\
\text { CISS - angażowanie się w czynności zastępcze }\end{array}$ & 0.36 & $<0.01$ & 0.42 & $<0.001$ & -0.39 & $<0.001$ \\
\hline $\begin{array}{l}\text { CISS - search for social contact } \\
\text { CISS - poszukiwanie kontaktów towarzyskich }\end{array}$ & -0.17 & 0.18 & -0.34 & $<0.05$ & 0.25 & $<0.05$ \\
\hline $\begin{array}{l}\text { CISS - avoidance-oriented style } \\
\text { CISS - styl skoncentrowany na unikaniu }\end{array}$ & 0.25 & $<0.05$ & 0.20 & 0.12 & -0.22 & 0.08 \\
\hline
\end{tabular}

Tab. 4. Results of a test of correlations between the application of styles of coping with stress according to CISS and dimensions of professional burnout according to $M B I$

Tab. 4. Wyniki testu związków między stosowaniem stylów radzenia sobie ze stresem według CISS a wymiarami wypalenia zawodowego wedtug $M B I$ 
Positive relations between particular abilities to fantasise and a search for social contact should also be noted $(r=0.25 ; p<0.05$, weak effect).

\section{Regression analysis}

A regression analysis for the effect of empathy and styles of coping with stress on professional burnout was performed for three models:

- model 1 - effect of styles of coping with stress on professional burnout;

- model 2 - effect of empathy on professional burnout;

- model 3 - joint effect of styles of coping with stress and empathy on professional burnout.

Due to the fact that only one dependent variable may be included in a linear regression analysis, with the use of principal component analysis (PCA) shown in Tab. 6, one dimension was distinguished, corresponding to the global results of professional burnout. This dimension explained $64 \%$ of variances of the three constituent dimensions of burnout. In addition, Tab. 6 shows common variability resources, namely a distinguished variance percentage of each dimension that was included in a given dimension. skoncentrowanym na unikaniu $(r=-0,25 ; p<0,05$, słaby efekt). Ponadto wystąpił istotny dodatni związek między skłonnością do odczuwania osobistej przykrości w odpowiedzi na silnie negatywne doświadczenia innych ludzi a stylem skoncentrowanym na emocjach $(r=0,43 ; p<0,01$, umiarkowany efekt).

$\mathrm{Na}$ uwagę zasługuje również istotny dodatni związek między indywidualnymi zdolnościami fantazjowania a poszukiwaniem kontaktów towarzyskich $(r=0,25$; $p<0,05$, słaby efekt).

\section{Analiza regresji}

Analizę regresji dotyczącą wpływu empatii i stylów radzenia sobie ze stresem na wypalenie zawodowe dokonano dla trzech modeli:

- model nr 1 - wpływ stylów radzenia sobie ze stresem na wypalenie zawodowe;

- model nr 2 - wpływ empatii na wypalenie zawodowe;

- model nr 3 - łączny wpływ stylów radzenia sobie ze stresem i empatii na wypalenie zawodowe.

Jako że do analizy regresji liniowej można wprowadzić tylko jedną zmienną zależną, za pomocą analizy

\begin{tabular}{|c|c|c|c|c|c|c|}
\hline & & $\begin{array}{c}\text { CISS - task-oriented } \\
\text { style } \\
\text { CISS-styl } \\
\text { skoncentrowany } \\
\text { na zadaniu }\end{array}$ & $\begin{array}{l}\text { CISS - emotion- } \\
\text { oriented style } \\
\text { CISS - styl } \\
\text { skoncentrowany } \\
\text { na emocjach }\end{array}$ & $\begin{array}{l}\text { CISS - engagement } \\
\text { in replacement } \\
\text { activities } \\
\text { CISS - angażowanie się } \\
\text { w czynności zastępcze }\end{array}$ & $\begin{array}{l}\text { CISS - search for } \\
\text { social contact } \\
\text { CISS - poszukiwanie } \\
\text { kontaktów towarzyskich }\end{array}$ & $\begin{array}{l}\text { CISS - avoidance- } \\
\text { oriented style } \\
\text { CISS - styl } \\
\text { skoncentrowany } \\
\text { na unikaniu }\end{array}$ \\
\hline \multirow{2}{*}{$\begin{array}{l}\text { IRI - assumption of a perspective } \\
|R| \text { - przyjmowanie perspektywy }\end{array}$} & $r$ & 0.34 & -0.17 & -0.37 & 0.14 & -0.25 \\
\hline & $p$ & $<0.05$ & 0.18 & $<0.05$ & 0.28 & $<0.05$ \\
\hline \multirow{2}{*}{$\begin{array}{l}\text { IRI - empathetic care } \\
|R| \text { - empatyczna troska }\end{array}$} & $r$ & 0.11 & 0.13 & -0.10 & 0.22 & 0.05 \\
\hline & $p$ & 0.37 & 0.30 & 0.43 & 0.08 & 0.70 \\
\hline \multirow{2}{*}{$\begin{array}{l}\text { IRI - personal distress } \\
|R| \text { - osobista przykrość }\end{array}$} & $r$ & -0.11 & 0.43 & 0.17 & 0.15 & 0.23 \\
\hline & $p$ & 0.37 & $<0.01$ & 0.17 & 0.24 & 0.06 \\
\hline \multirow{2}{*}{$\begin{array}{l}\text { IRI - fantasy } \\
|R| \text { - fantazja }\end{array}$} & $r$ & 0.20 & 0.20 & -0.02 & 0.25 & 0.12 \\
\hline & $p$ & 0.11 & 0.11 & 0.86 & $<0.05$ & 0.33 \\
\hline
\end{tabular}

Tab. 5. Results of a test of correlations between the application of styles of coping with stress according to CISS and IRI empathy scale Tab. 5. Wyniki testu związków między stosowaniem stylów radzenia sobie ze stresem według CISS a skala empatii IRI

\begin{tabular}{|c|c|c|c|c|c|}
\hline \multirow{2}{*}{$\begin{array}{l}\text { Professional burnout dimension (MBI) } \\
\text { Wymiar wypalenia zawodowego (MBI) }\end{array}$} & \multirow{2}{*}{$\begin{array}{c}\text { Constituent } \\
\text { Składowa }\end{array}$} & \multicolumn{2}{|c|}{$\begin{array}{l}\text { Initial eigen values } \\
\text { Początkowe wartości własne }\end{array}$} & \multicolumn{2}{|c|}{$\begin{array}{l}\text { Common variability resources } \\
\text { Zasoby zmienności wspólnej }\end{array}$} \\
\hline & & $\begin{array}{l}\text { Overall } \\
\text { Ogótem }\end{array}$ & $\begin{array}{l}\text { Variance \% } \\
\% \text { wariancii }\end{array}$ & $\begin{array}{c}\text { Initial } \\
\text { Początkowe }\end{array}$ & $\begin{array}{l}\text { After distinguishing } \\
\text { Po wyodrębnieniu }\end{array}$ \\
\hline $\begin{array}{l}\text { Emotional exhaustion } \\
\text { Wyczerpanie emocjonalne }\end{array}$ & 0.86 & \multirow{3}{*}{1.92} & \multirow{3}{*}{63.93} & 1.00 & 0.74 \\
\hline $\begin{array}{l}\text { Depersonalisation } \\
\text { Depersonalizacja }\end{array}$ & 0.88 & & & 1.00 & 0.78 \\
\hline $\begin{array}{l}\text { Lowered sense of personal achievements } \\
\text { Obniżone poczucie osiagnięć osobistych }\end{array}$ & -0.63 & & & 1.00 & 0.40 \\
\hline
\end{tabular}

Tab. 6. Results of principal component analysis (PCA) and common variability resources for the distinguished dimension Tab. 6. Wynik analizy składowych głównych (PCA) i zasoby zmienności wspólnej dla wyodrębnionego wymiaru 
In order to perform a regression analysis for the effects of empathy and styles of coping with stress on professional burnout in models 1 and 2, the forward selection method was applied. However, for the purpose of the regression analysis for model 3, the influence of both empathy and styles of coping with stress on professional burnout, the introduction method was applied, so that it would be possible to become familiar with the values of $\beta$ coefficients when all previously-significant predicators were considered in the model. The results of ANOVA for the resulting models are shown in Tab. 7. According to these results, in the regression model 1 there was an improvement in the prediction capability with regard to the simple average $\left(F=20.58 ; p<0.001 ; \Delta R^{2}=0.48\right)$. Model 1 explained $48 \%$ of variances of professional burnout in the study group. According to the ANOVA results for model 2, there was a significant improvement of model 2 in the prediction capabilities with regard to the simple average ( $F=7.46$; $p<0.001 ; \Delta R^{2}=0.17$ ). Model 2 explained $17 \%$ of variances of professional burnout in the study group. According to the ANOVA results for model 3, there was a significant improvement of model 3 in its prediction capabilities with regard to the simple average $(F=11.94 ; p<0.001$; $\Delta R^{2}=0.47$ ). Model 3 explained $47 \%$ of variances of professional burnout in the study group. Moreover, a DurbinWatson test was performed to test the assumption regarding errors in the models analysed (Tab. 7) according to which the statistical value for each of these models was very close to the recommended value of 2.00 , and fell within a range of $1-3$, which leads to the conclusion that this assumption was satisfied.

The regression analysis based on model 1 (Tab. 8) showed that significant predictors of professional burnout were the emotion-oriented style, search for social contact and avoidance-oriented style. Along with an increased application of the search for social contact, professional burnout decreased ( $\beta=-0.54)$, whereas in the case of the emotion-oriented style $(\beta=-0.41)$ and the avoidance-oriented style $(\beta=-0.36)$, the situation was the opposite. The collinearity statistics exclude a collinearity between the

\begin{tabular}{|c|c|c|c|c|}
\hline $\begin{array}{c}\text { Regression } \\
\text { Regresja }\end{array}$ & $\boldsymbol{F}$ & $\boldsymbol{p}$ & $\boldsymbol{\Delta} \boldsymbol{R}^{2}$ & $\begin{array}{c}\text { Durbin-Watson } \\
\text { statistics } \\
\text { Statystyka } \\
\text { Durbina-Watsona }\end{array}$ \\
\hline $\begin{array}{c}\text { Regression model 1 } \\
\text { Model regresji } \text { 1 1 }\end{array}$ & 20.58 & $<0.001$ & 0.48 & 2.35 \\
\hline $\begin{array}{c}\text { Regression model 2 } \\
\text { Model regresji inr 2 }\end{array}$ & 7.46 & $<0.001$ & 0.17 & 1.80 \\
\hline $\begin{array}{c}\text { Regression model 3 } \\
\text { Model regresji } \text { ir 3 }\end{array}$ & 11.94 & $<0.001$ & 0.47 & 2.35 \\
\hline
\end{tabular}

Tab. 7. Results of ANOVA for three models of linear regression Tab. 7. Wyniki ANOVA dla trzech modeli regresji liniowej składowych głównych (principal component analysis, PCA) wyodrębniono jeden wymiar, który odpowiadał globalnym wynikom wypalenia zawodowego (tab. 6). Wyjaśniał on $64 \%$ wariancji trzech wymiarów wypalenia. Dodatkowo w tab. 6 przedstawiono zasoby zmienności wspólnej, czyli to, jaki procent wariancji każdego z wymiarów został zawarty w wyodrębnionym wymiarze.

Do wykonania analizy regresji dla wpływu empatii i stylów radzenia sobie ze stresem na wypalenie zawodowe w przypadku modeli nr 1 i nr 2 użyto metody selekcji postępującej. Natomiast do analizy regresji dla modelu nr 3 - wpływu zarówno empatii, jak i stylów radzenia sobie ze stresem na wypalenie zawodowe - wybrano metodę wprowadzenia, tak by można było się zapoznać $z$ wartościami współczynników $\beta$, gdy wszystkie uprzednio istotne predyktory zostały uwzględnione w modelu. Wyniki ANOVA dla stworzonych modeli zawarto $\mathrm{w}$ tab. 7. W przypadku modelu regresji nr 1 wykazano, $\mathrm{iż} \mathrm{w}$ istotnym stopniu poprawił on zdolności predykcyjne względem zwykłej średniej $(F=20,58 ; p<0,001$; $\left.\Delta R^{2}=0,48\right)$. Model nr 1 wyjaśniał $48 \%$ wariancji wypalenia zawodowego w badanej grupie. Wyniki ANOVA dla modelu nr 2 także wykazały, że w istotnym stopniu poprawił on zdolności predykcyjne względem zwykłej średniej $\left(F=7,46 ; p<0,001 ; \Delta R^{2}=0,17\right)$. Model nr 2 wyjaśniał $17 \%$ wariancji wypalenia zawodowego w badanej grupie. Również wyniki ANOVA dla modelu nr 3 wykazały, iż w istotnym stopniu poprawił on zdolności predykcyjne względem zwykłej średniej $(F=11,94 ; p<0,001$; $\left.\Delta R^{2}=0,47\right)$. Model nr 3 wyjaśniał $47 \%$ wariancji wypalenia zawodowego w badanej grupie. Dodatkowo wykonano test Durbina-Watsona, testujący założenie o niezależności błędów w analizowanych modelach (tab. 7). Wskazał on, że wartość statystyki dla każdego z modeli była bardzo bliska wartości zalecanej - 2,00 i mieściła się w przedziale od 1 do 3, w związku z czym można uznać, iż to założenie zostało spełnione.

Analiza regresji bazująca na modelu nr 1 wykazała (tab. 8), że istotnymi predyktorami wypalenia zawodowego były styl skoncentrowany na emocjach, poszukiwanie kontaktów towarzyskich oraz styl skoncentrowany na unikaniu. Wraz ze wzrostem poszukiwania kontaktów towarzyskich malało wypalenie zawodowe $(\beta=-0,54)$, a w przypadku stylu skoncentrowanego na emocjach $(\beta=0,41)$ i stylu skoncentrowanego na unikaniu $(\beta=0,36)$ było na odwrót. Statystyki współliniowości wykluczają współliniowość między predyktorami (czynnik inflacji wariancji - variance inflation factor, VIF - w każdym przypadku był niższy od 10, a tolerancja - większa od 0,1). Oznacza to, że każdy z predyktorów mierzył odrębne od pozostałych zjawisko, co czyni zasadnym analizowanie regresji liniowej przy ich udziale.

Analiza regresji bazująca na modelu nr 2 wykazała (tab. 9), że istotnymi predyktorami wypalenia zawodowego były dwie spośród czterech skal empatii: przyjmowanie cudzej perspektywy i osobista przykrość. 
predictors (variance inflation factor, VIF in each case was below 10, and tolerance was over 0.1 ). This means that each of the predictors measured a separate object/phenomenon, which justifies analysing linear regression with the use of these predictors.

The regression analysis on the basis of model 2 (Tab. 9) showed that the significant predictors of professional burnout were two out of four scales of the types of empathy: assumption of someone else's perspective and personal distress. Along with an increase in the tendency to empathise through the assumption of someone else's perspective, the tendency for professional burnout decreased $(\beta=-0.45)$, whereas the sense of distress due to the negative experience of other people strengthened the sense of professional burnout $(\beta=0.37)$. The collinearity statistics exclude collinearity between the predictors (VIF in each case was below 10, whereas the tolerance was over 0.1 ). This means that each of the predictors measured a separate object/phenomenon, which justifies analysing linear regression with the use of these predictors.

The linear regression analysis on the basis of model 3 showed (Tab. 10) that the significant predictors of professional burnout were emotion-oriented style, search for social contact and avoidance-oriented styles. However, in this model no scale of empathy was confirmed as a predictor. Along with an increase in the application of search
Wraz ze wzrostem skłonności do empatyzowania przez przyjmowanie cudzej perspektywy malała skłonność do wypalenia zawodowego $(\beta=-0,45)$, a odczuwanie przykrości na skutek negatywnych doświadczeń innych ludzi nasilało poczucie wypalenia zawodowego $(\beta=0,37)$. Statystyki współliniowości wykluczają współliniowość między predyktorami (VIF w każdym przypadku był niższy od 10, a tolerancja - większa od 0,1). Oznacza to, że każdy z predyktorów mierzył odrębne od pozostałych zjawisko, co czyni zasadnym analizowanie regresji liniowej przy ich udziale.

Analiza regresji bazująca na modelu nr 3 wykazała (tab. 10), że istotnymi predyktorami wypalenia zawodowego były styl skoncentrowany na emocjach, poszukiwanie kontaktów towarzyskich i styl skoncentrowany na unikaniu. Nie potwierdzono natomiast żadnej ze skal empatii jako predyktora. Wraz ze wzrostem poszukiwania kontaktów towarzyskich malało wypalenie zawodowe $(\beta=-0,54)$, a w przypadku stylu skoncentrowanego na emocjach $(\beta=0,42)$ i stylu skoncentrowanego na unikaniu było na odwrót $(\beta=0,37)$. Statystyki współliniowości pozwalają odrzucić założenie, jakoby między predyktorami zachodziła współliniowość (VIF w każdym przypadku był niższy od 10, a tolerancja większa od 0,1). Oznacza to, że każdy z predyktorów mierzył odrębne od pozostałych zjawisko, co czyni

\begin{tabular}{|c|c|c|c|c|c|c|c|}
\hline & \multicolumn{2}{|c|}{$\begin{array}{l}\text { Non-standardised coefficients } \\
\text { Wspótczynniki niestandaryzowane }\end{array}$} & \multirow{2}{*}{$\begin{array}{c}\text { Standardised coefficients } \\
\text { Wspótczynniki standaryzowane } \\
\boldsymbol{\beta}\end{array}$} & \multirow{2}{*}{$t$} & \multirow{2}{*}{$p$} & \multicolumn{2}{|c|}{$\begin{array}{l}\text { Collinearity statistics } \\
\text { Statystyki wspólliniowości }\end{array}$} \\
\hline & $B$ & SE & & & & $\begin{array}{l}\text { Tolerance } \\
\text { Tolerancja }\end{array}$ & VIF \\
\hline $\begin{array}{c}\text { (Constant) } \\
\text { (Stała) }\end{array}$ & -1.54 & 0.61 & & -2.53 & 0.01 & & \\
\hline $\begin{array}{l}\text { CISS - emotion-oriented style } \\
\text { CISS - styl skoncentrowany na emocjach }\end{array}$ & 0.05 & 0.01 & 0.41 & 3.76 & 0.00 & 0.68 & 1.48 \\
\hline $\begin{array}{l}\text { CISS - search for social contact } \\
\text { CISS - poszukiwanie kontaktów towarzyskich }\end{array}$ & -0.15 & 0.03 & -0.54 & -4.73 & 0.00 & 0.63 & 1.58 \\
\hline $\begin{array}{l}\text { CISS - avoidance-oriented style } \\
\text { CISS - styl skoncentrowany na unikaniu }\end{array}$ & 0,04 & 0,01 & 0,36 & 2,76 & 0,01 & 0.47 & 2.11 \\
\hline
\end{tabular}

Tab. 8. Linear regression coefficient values for model 1

Tab. 8. Wartości współczynników regresji liniowej modelu nr 1

\begin{tabular}{|c|c|c|c|c|c|c|c|}
\hline & \multicolumn{2}{|c|}{$\begin{array}{l}\text { Non-standardised coefficients } \\
\text { Wspótczynniki niestandaryzowane }\end{array}$} & \multirow{2}{*}{$\begin{array}{c}\text { Standardised coefficients } \\
\text { Wspókczynniki standaryzowane } \\
\boldsymbol{\beta}\end{array}$} & \multirow{2}{*}{$t$} & \multirow{2}{*}{$p$} & \multicolumn{2}{|c|}{$\begin{array}{l}\text { Collinearity statistics } \\
\text { Statystyki współliniowości }\end{array}$} \\
\hline & $B$ & $S E$ & & & & $\begin{array}{c}\text { Tolerance } \\
\text { Tolerancja }\end{array}$ & VIF \\
\hline $\begin{array}{l}\text { IRI - assumption of a perspective } \\
|R| \text { - przyjmowanie perspektywy }\end{array}$ & -0.11 & 0.03 & -0.45 & -3.52 & $<0.001$ & 0.82 & 1.22 \\
\hline $\begin{array}{l}\text { IRI - personal distress } \\
|R| \text { - osobista przykrość }\end{array}$ & 0.08 & 0.03 & 0.37 & 2.93 & $<0.001$ & 0.82 & 1.22 \\
\hline
\end{tabular}

Tab. 9. Values of linear regression coefficients for model 2

Tab. 9. Wartości współczynników regresji liniowej modelu nr 2 


\begin{tabular}{|c|c|c|c|c|c|c|c|}
\hline & \multicolumn{2}{|c|}{$\begin{array}{l}\text { Non-standardised coefficients } \\
\text { Wspótcynniki niestandaryzowane }\end{array}$} & \multirow{2}{*}{$\begin{array}{c}\text { Standardised coefficients } \\
\text { Wspótczynniki standaryzowane } \\
\boldsymbol{\beta}\end{array}$} & \multirow{2}{*}{$t$} & \multirow{2}{*}{$p$} & \multicolumn{2}{|c|}{$\begin{array}{l}\text { Collinearity statistics } \\
\text { Statystyki wspótliniowośc }\end{array}$} \\
\hline & $B$ & $S E$ & & & & $\begin{array}{c}\text { Tolerance } \\
\text { Tolerancja }\end{array}$ & VIF \\
\hline $\begin{array}{c}\text { (Constant) } \\
\text { (Stała) }\end{array}$ & -1.59 & 0.83 & & -1.93 & 0.06 & & \\
\hline $\begin{array}{l}\text { IRI - empathic care } \\
|R| \text { - empatyczna troska }\end{array}$ & 0.00 & 0.04 & 0.02 & 0.13 & 0.90 & 0.39 & 2.59 \\
\hline $\begin{array}{l}\text { IRI - personal distress } \\
|R| \text { - osobista pryykrość }\end{array}$ & 0.00 & 0.04 & -0.02 & -0.11 & 0.92 & 0.34 & 2.95 \\
\hline $\begin{array}{l}\text { CISS - emotion-oriented style } \\
\text { CISS - styl skoncentrowany na emocjach }\end{array}$ & 0.05 & 0.01 & 0.42 & 3.37 & $<0.001$ & 0.55 & 1.81 \\
\hline $\begin{array}{l}\text { CISS - avoidance-oriented style } \\
\text { CISS - styl skoncentrowany na unikaniu }\end{array}$ & 0.04 & 0.02 & 0.37 & 2.68 & $<0.01$ & 0.45 & 2.21 \\
\hline $\begin{array}{l}\text { CISS - search for social contact } \\
\text { CISS - poszukiwanie kontaktów towarzyskich }\end{array}$ & -0.15 & 0.03 & -0.54 & -4.47 & $<0.001$ & 0.58 & 1.73 \\
\hline
\end{tabular}

Tab. 10. Values of linear regression coefficients for model 3

Tab. 10. Wartości wspótczynników regresji liniowej modelu nr 3

for social contact, the degree of professional burnout decreased $(\beta=-0.54)$, whereas for the emotion-oriented style $(\beta=0.42)$ and avoidance-oriented style, the situation was the opposite $(\beta=0.37)$. Collinearity statistics make it possible to reject the assumption that there is collinearity between the predictors (VIF in each case was below 10, whereas the tolerance was over 0.1). This means that each of the predictors measured a separate object/phenomenon, which justifies analysing linear regression with the use of these predictors. The decline of significance in the effect of empathy on professional burnout in this model means that a complete mediation occurred in this case. The variance previously explained by empathy is explained in this model by the styles of coping with stress.

\section{DISCUSSION}

The study conducted among psychiatric nurses may be of high practical significance in preventing negative effects of stress because a comprehensive literature review (Abdalrahim, 2009) shows that they experience stress in the workplace mainly when they are in contact with patients or co-workers, and have little social support. They rarely apply the constructive styles of coping with stress that are focused on problem-solving. This leads to professional burnout in psychiatric nurses, and thus it is recommended to incorporate educational elements directed at coping with stress into the teaching curricula, to include supervision and raise social competences of nurses in the workplace. Moreover, stressors should be identified, and their influence should be limited through reorganisation (Edwards et al., 2000). The development of empathy is also important, since numerous studies reveal an zasadnym analizowanie regresji liniowej przy ich udziale. Zanik istotności we wpływie empatii na wypalenie zawodowe w modelu nr 3 wskazuje, że wystąpiła tu mediacja całkowita. Wariancję wcześniej wyjaśnianą przez empatię wyjaśniały w tym modelu style radzenia sobie ze stresem.

\section{OMÓWIENIE}

Badania przeprowadzone wśród pielęgniarek psychiatrycznych mogą mieć duże znaczenie praktyczne w zapobieganiu negatywnym skutkom stresu, gdyż na podstawie analizy obszernej literatury zostało stwierdzone (Abdalrahim, 2013), że ta grupa zawodowa doświadcza stresu w miejscu pracy, głównie w kontaktach z pacjentami i współpracownikami, oraz ma niskie wsparcie społeczne. Pielęgniarki psychiatryczne rzadko stosują konstruktywne style radzenia sobie ze stresem, zorientowane na rozwiązywanie problemów. Prowadzi to do wypalenia zawodowego, w związku z czym zalecane są: włączenie do programów kształcenia treści ukierunkowanych na radzenie sobie ze stresem, wprowadzenie superwizji i podniesienie kompetencji społecznych pielęgniarek w miejscu pracy. Ponadto należy zidentyfikować stresory i przez reorganizację stanowisk ograniczyć ich oddziaływanie (Edwards et al., 2000). Nie bez znaczenia jest rozwijanie empatii, ponieważ w wielu badaniach stwierdzono przeciwną korelację empatii z wypaleniem zawodowym (Ferri et al., 2015; Omdahl i O’Donnell, 1999; Pålsson et al., 1996; Wilkinson et al., 2017). Neumann i wsp. (2009) stwierdzili, że empatii można się nauczyć. Pielęgniarki, które uczestniczyły w treningu empatii, zostały zidentyfikowane jako uzyskujące wyższe wyniki empatii niż te, które nie przeszły szkolenia (Kuo et al., 2012). 
burnout (Ferri et al., 2015; Omdahl and O'Donnell 1999; Pålsson et al., 1996; Wilkinson et al., 2017). Neumann et al. (2009) found that it was possible to learn empathy. Nurses that took part in empathy training were identified as having higher empathy levels than nurses that did not participate (Kuo et al., 2012). Employees who are capable of developing healthy empathetic involvement are especially important, since empathy in practical health care has been found to improve the health of patients (Lelorain et al., 2012; Parkin et al., 2014) and prevent professional burnout (Raižienè and Endriulaitienè, 2007). According to researchers, higher education institutions that provide education to nurses and managers bear the responsibility for implementing measures to raise and maintain appropriate empathy levels, and must cooperate to select a strategic direction for the development of empathy and involvement (Burks et al., 2012).

Based on previous Polish (Wilczek-Ruzyczka and Kalicinska, 2015) findings, psychiatric nurses experience a high level of stress and professional burnout in the dimensions of emotional exhaustion and depersonalisation. However, according to the presented study, people with a higher score in the empathy scale of assumption of a perspective and who more often choose the task-oriented style of coping with stress, namely the constructive one, are less vulnerable to the negative effects of professional burnout both in the dimension of depersonalisation and lowered sense of personal achievements. In turn, the psychiatric nurses that experience a more significant personal distress and apply non-constructive styles of coping with stress, and focus on emotions and engagement in replacement activities, are the ones more emotionally exhausted. These results are similar to those obtained in the study carried out among nephrology nurses by Wilczek-Rużyczka and Michalska (2018), but different from the conclusions of Kinman and Leggetter (2016), based on which emotional exhaustion among nurses and nursing students was inversely correlated with focusing on emotions.

Although the regression analyses conducted separately for the styles of coping with stress and the types of empathy showed that the significant predictors of professional burnout understood holistically included both the focus on emotions, search for social contact and focus on avoidance, and two out of four scales of types of empathy, in the regression model analysing simultaneously the preferred styles and types of empathy as significant predictors, only the following were confirmed: focus on emotions, search for social contact, and focus on avoidance. The application of these three non-constructive styles of coping with stress leads not only to professional burnout, but may also adversely influence teamwork. For example, previous studies showed difficulties in the adaptation process in nurses that applied the emotional style of coping with stress (Thirioux et al., 2016; Wilczek-Ruzyczka and Kalicinska, 2015).
Pracownicy będący w stanie rozwinąć zdrowe zaangażowanie empatyczne są szczególnie ważni, okazało się bowiem, że w praktyce opieki zdrowotnej empatia poprawia stan zdrowia pacjentów (Lelorain et al., 2012; Parkin et al., 2014) i zapobiega wypaleniu zawodowemu personelu (Raižienè i Endriulaitienè, 2007). Naukowcy twierdzą, że na uczelniach kształcących pielęgniarki i na menadżerach opieki zdrowotnej spoczywa obowiązek wdrażania środków w celu podnoszenia i utrzymania poziomu empatii oraz że muszą oni współpracować, aby rozwinąć strategiczny kierunek zwiększania empatii i zaangażowania (Burks et al., 2012).

Wcześniejsze polskie doniesienia (Wilczek-Ruzyczka i Kalicinska, 2015) wskazują, iż pielęgniarki psychiatryczne cechują się wysokim poziomem stresu oraz wypalenia zawodowego w wymiarach „wyczerpanie emocjonalne” i „depersonalizacja”. Z kolei z prezentowanych badań wynika, że osoby, które charakteryzują się wyższym poziomem w skali empatii „przyjmowanie perspektywy” i częściej wybierają styl radzenia sobie ze stresem skoncentrowany na zadaniu - czyli konstruktywny - w mniejszym stopniu narażone są na negatywne skutki wypalenia zawodowego, zarówno w wymiarze depersonalizacji, jak i obniżonego poczucia osiągnięć osobistych. Natomiast bardziej wyczerpane emocjonalnie są badane pielęgniarki psychiatryczne odczuwające w większym stopniu osobistą przykrość i stosujące niekonstruktywne style radzenia sobie ze stresem: skoncentrowanie na emocjach i angażowanie się w czynności zastępcze. Uzyskane wyniki są podobne do rezultatów badań przeprowadzonych wśród pielęgniarek nefrologicznych przez Wilczek-Rużyczkę i Michalską (2018), ale odmienne od ustaleń Kinman i Leggetter (2016), zgodnie z którymi wyczerpanie emocjonalne pielęgniarek i studentów pielęgniarstwa było przeciwnie związane z koncentracją na emocjach.

Chociaż analizy regresji przeprowadzone oddzielnie dla stylów radzenia sobie ze stresem i rodzajów empatii wykazały, że istotnymi predyktorami wypalenia zawodowego rozumianego całościowo były zarówno koncentracja na emocjach, poszukiwanie kontaktów towarzyskich i koncentracja na unikaniu, jak i dwa spośród czterech rodzajów empatii, to w modelu regresji analizującym jednocześnie preferowane style i rodzaje empatii jako istotne predyktory potwierdzone zostały jedynie koncentracja na emocjach, poszukiwanie kontaktów towarzyskich i koncentracja na unikaniu. Stosowanie tych trzech niekonstruktywnych stylów nie tylko przyczynia się do wypalenia zawodowego, ale też może niekorzystnie wpływać na pracę w zespole we wcześniejszych badaniach wykazano przykładowo utrudnienie procesu adaptacyjnego w przypadku pielęgniarek wykorzystujących emocjonalny styl radzenia sobie ze stresem (Thirioux et al., 2016; Wilczek-Ruzyczka i Kalicinska, 2015). 


\section{CONCLUSIONS}

On the basis of study results and foregoing considerations, the following conclusions may be drawn:

1. There were significant correlations between the level of empathy, application of styles of coping with stress and professional burnout syndrome in the group of psychiatric nurses participating in the study.

2. In the study group of psychiatric nurses, the individuals with higher levels of empathy than other respondents more often choose the task-oriented coping style, and are less vulnerable to professional burnout.

3. The application of non-constructive styles of coping with stress by psychiatric nurses participating in the study contributes significantly to professional burnout.

4. The study results provide evidence justifying the introduction of empathy training (with a special focus on the development of cognitive empathy and assumption of perspective) and also educational programmes concerning coping with stress in the education process.

5. The presented study, which is the first study to address the analysed variables in the group of psychiatric nurses, should be continued in a larger study group with the introduction of comparative groups representing other nursing specialties.

\section{Conflict of interest}

The author does not declare any financial or personal links with other persons or organisations that might adversely affect the content of the publication or claim any right to the publication.

\section{Funding/Support and role of the sponsor}

The study was financed with the use of funds from the Ministry of Science and Higher Education for scientific and development research within its status activity (No. WPiNH/DS/11/2018 "Diagnosis and interventions to prevent occupational burnout and alleviate its symptoms" head dr hab. Ewa Wilczek-Rużyczka).

\section{References / Piśmiennictwo}

Abdalrahim AA: Stress and coping among psychiatric nurses. Middle East J Nurs 2013; 7: 31-37.

Burks DJ, Youll LK, Durtschi JP: The empathy-altruism association and its relevance to health care professions. Soc Behav Pers 2012; 40: 395-400.

Davis MH: Empatia. O umiejętności współodczuwania. Gdańskie Wydawnictwo Psychologiczne, Gdańsk 2001.

Edwards D, Burnard P, Coyle D et al.: Stress and burnout in community mental health nursing: a review of the literature. J Psychiatr Ment Health Nurs 2000; 7: 7-14.

Endler NS, Parker JD: Multidimensional assessment of coping: a critical evaluation. J Pers Soc Psychol 1990; 58: 844-854.

Ferri P, Guerra E, Marcheselli L et al.: Empathy and burnout: an analytic cross-sectional study among nurses and nursing students. Acta Biomed 2015; 86 Suppl 2: 104-115.

George D, Mallery P: SPSS for Windows Step by Step: A Simple Study Guide and Reference. 17.0 update. $10^{\text {th }}$ ed., Pearson, Boston 2010.
WNIOSKI

Na podstawie wyników badań i powyższych rozważań można wysunąć następujące wnioski:

1. W grupie pielęgniarek psychiatrycznych wykazano istotne związki między poziomem empatii, stosowaniem stylów radzenia sobie ze stresem a zespołem wypalenia zawodowego.

2. W badanej grupie pieleggniarek psychiatrycznych osoby, które charakteryzują się wyższym poziomem empatii, częściej wybierają zadaniowy styl radzenia sobie ze stresem i są w mniejszym stopniu narażone na wypalenie zawodowe.

3. Stosowanie niekonstruktywnych stylów radzenia sobie ze stresem przez badane pielęgniarki psychiatryczne przyczynia się w sposób istotny do wypalenia zawodowego.

4. Wyniki badań wskazują na zasadność wprowadzenia do procesu kształcenia pielęgniarek treningu empatii (ze szczególnym naciskiem na rozwój empatii poznawczej - przyjmowanie perspektywy, gdyż sprzyja to zdolności do zachowań empatycznych) i programów edukacyjnych dotyczących radzenia sobie ze stresem.

5. Prezentowane badania, po raz pierwszy uwzględniające analizowane zmienne w grupie pielęgniarek psychiatrycznych, należy kontynuować w liczniejszej grupie badawczej - z grupami porównawczymi, reprezentującymi inne specjalności pielęgniarskie.

\section{Konflikt interesów}

Autorka nie zgłasza żadnych finansowych ani osobistych powiązań $z$ innymi osobami lub organizacjami, które mogłyby negatywnie wpłynąć na treść publikacji oraz rościć sobie prawo do tej publikacji.

\section{Źródło finansowania}

Badanie zostało sfinansowane ze środków Ministerstwa Nauki i Szkolnictwa Wyższego na badania naukowe i rozwojowe w ramach działalności statutowej (nr WPiNH/DS/11/2018, „Diagnozowanie oraz interwencje zapobiegające wypaleniu zawodowemu $i$ łagodzace jego objawy" - dr hab. Ewa Wilczek-Rużyczka, prof. nadzw.).

Grygorczyk A: Pojęcie stresu w medycynie i psychologii. Psychiatria 2008; 5: 111-115.

Kinman G, Leggetter S: Emotional labour and wellbeing: what protects nurses? Healthcare (Basel) 2016; 4: pii: E89.

Kuo JC, Cheng JF, Chen YL et al.: An exploration of empathy and correlates among Taiwanese nurses. Jpn J Nurs Sci 2012; 9: 169-176.

Lelorain S, Brédart A, Dolbeault S et al.: A systematic review of the associations between empathy measures and patient outcomes in cancer care. Psychooncology 2012; 21: 1255-1264.

Maslach C, Jackson SE: The measurement of experienced burnout. J Occup Behav 1981; 2: 99-113.

Maslach C, Schaufeli WB, Leiter MP: Job burnout. Annu Rev Psychol 2001; 52: 397-422.

Neumann M, Bensing J, Mercer S et al.: Analyzing the "nature" and "specific effectiveness" of clinical empathy: a theoretical overview and contribution towards a theory-based research agenda. Patient Educ Couns 2009; 74: 339-346. 
Omdahl BL, O’Donnell C: Emotional contagion, empathic concern and communicative responsiveness as variables affecting nurses' stress and occupational commitment. J Adv Nurs 1999; 29: 1351-1359.

Pålsson MB, Hallberg IR, Norberg A et al.: Burnout, empathy and sense of coherence among Swedish district nurses before and after systematic clinical supervision. Scand J Caring Sci 1996; 10: 19-26.

Parkin T, de Looy A, Farrand P: Greater professional empathy leads to higher agreement about decisions made in the consultation. Patient Educ Couns 2014; 96: 144-150.

Raižienè S, Endriulaitienė A: The relations among empathy, occupational commitment, and emotional exhaustion of nurses. Medicina (Kaunas) 2007; 43: 425-431.

Siegrist J, Starke D, Chandola T et al.: The measurement of effortreward imbalance at work: European comparisons. Soc Sci Med 2004; 58: 1483-1499.
Strus W: Dojrzałość emocjonalna a funkcjonowanie moralne. Wydawnictwo Liberi Libri, Warszawa 2012.

Thirioux B, Birault F, Jaafari N: Empathy is a protective factor of burnout in physicians: new neuro-phenomenological hypotheses regarding empathy and sympathy in care relationship. Front Psychol 2016; 7: 763.

Wilczek-Ruzyczka E, Kalicinska M: Occupational stress and burnout among Polish psychiatric nurses. European Health Psychologist 2015; 17: 158-164.

Wilczek-Rużyczka E: Empatia pracowników medycznych. Wolters Kluwer Polska SA, Warszawa 2017.

Wilczek-Rużyczka E, Michalska W: Empatia jako czynnik przeciwdziałający wypaleniu zawodowemu pielęgniarek nefrologicznych. Forum Nefrologiczne 2018; 11: 134-141.

Wilkinson H, Whittington R, Perry L et al.: Examining the relationship between burnout and empathy in healthcare professionals: a systematic review. Burn Res 2017; 6: 18-29. 